\title{
PROTEÍNA E QUALIDADE DE SEMENTES DE FEIJÃO (Phaseolus vulgaris L.) EM FUNÇÃO DA ADUBAÇÃO NITROGENADA EM PLANTIO DIRETO ${ }^{1}$
}

\author{
FRANCISCO GUILHIEN GOMES JUNIOR²; MARCO EUSTÁQUIO DE SÁ
}

\begin{abstract}
RESUMO - Além de limitar a produtividade do feijoeiro, a deficiência de nitrogênio pode resultar na produção de sementes com baixo teor de proteína e baixo potencial fisiológico. Nesta pesquisa foram avaliados os efeitos da adubação nitrogenada em cobertura sobre o teor de proteína e o potencial fisiológico de sementes de feijão das cultivares (cv.) IPR Juriti e Pérola, cultivadas em parcelas (solo tipo $=$ Latossolo Vermelho Distrófico), em sistema de plantio direto sob densa palhada de milheto na Estação Experimental da UNESP - Campus de Ilha Solteira, em Selvíria, MS (classificação climática de Köppen $=$ Aw), durante o outono (março/junho) e inverno (junho/setembro) de 2005. Para cada cultivar foi utilizado o delineamento em blocos casualizados, com quatro repetições e o arranjo fatorial $(5 \times 2)$ entre doses de nitrogênio $\left(0,30,60,90\right.$ e $\left.120 \mathrm{~kg} \cdot \mathrm{ha}^{-1}\right)$ aplicadas em cobertura (na forma de uréia, contendo $45 \%$ de $\mathrm{N}$ ) nos estádios fenológicos $\mathrm{V}_{4-3} \mathrm{e}_{4-6}$, correspondentes à completa emissão da terceira e sexta folha trifoliolada da haste principal. A aplicação de até $120 \mathrm{~kg}^{-h a^{-1}}$ de N no estádio fenológico $\mathrm{V}_{4-3}$ promoveu maior acúmulo de proteína bruta na semente (dose $0=17,6 \%$ e 16,3\%; 120 kg.ha ${ }^{-1}$ de $\mathrm{N}=24,1 \%$ e 22,3\% para as cv. IPR Juriti e Pérola, respectivamente) em relação ao estádio fenológico $\mathrm{V}_{4-6}$ (dose $0=19,2 \%$ e 18,3\%; $120 \mathrm{~kg}$ ha $^{-1}$ de $\mathrm{N}=21,3 \%$ e 20,3\% para as cv. IPR Juriti e Pérola, respectivamente). O teor de proteína solúvel correspondeu a cerca de $90 \%$ da proteína bruta da semente da cv. IPR Juriti, contra $72 \%$ da cv. Pérola. As albuminas e as glutelinas representaram cerca de $80 \%$ da proteína solúvel da semente e as prolaminas a menor fração, $0,6 \%$. Conclui-se que a aplicação de até $120 \mathrm{~kg} \cdot$ ha $^{-1}$ de $\mathrm{N}$ no estádio fenológico $\mathrm{V}_{4-3}$, $\mathrm{em}$ sistema de plantio direto sob densa quantidade de palha de milheto, propicia maior acúmulo de proteína bruta na semente de feijão em relação à aplicação no estádio $\mathrm{V}_{4-6^{\circ}}$. A dose de $90 \mathrm{~kg} \cdot \mathrm{ha}^{-1}$ de $\mathrm{N}$ propicia maior acúmulo de proteína solúvel na semente, sem, contudo, exercer influência acentuada sobre o seu potencial fisiológico.
\end{abstract}

Termos para indexação: albuminas, glutelinas, potencial fisiológico, proteína solúvel.

\section{PROTEIN CONTENT AND COMMON BEAN (Phaseolus vulgaris L.) SEED QUALITY IN RELATIONSHIP TO NITROGEN FERTILIZATION IN A NO-TILLAGE SYSTEM}

\begin{abstract}
Nitrogen limitation in the common bean (Phaseolus vulgaris L.) produces reduced productivity and seeds with low protein content and physiological quality. We assessed the effects of nitrogen fertilizer side dressing on the protein content and physiological quality of the seeds of $P$. vulgaris L. cultivars (cv.) IPR Juriti and Pérola grown in plots (soil type = Dystrophic Red Latosol) using a no-tillage system under a thick mulch of millet residues at the Experimental Station of UNESP - Ilha Solteira campus, located in Selvíria, MS (Köppen climate type = Aw) during autumn (March/ June) and winter (June/September) 2005. For each cultivar, a randomized block experimental design
\end{abstract}

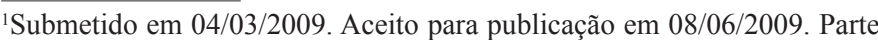
da Dissertação de Mestrado do primeiro autor apresentada à Universidade Estadual Paulista "Júlio de Mesquita Filho" (UNESP) - Campus de Ilha Solteira. Desenvolvido com apoio financeiro da FAPESP.

${ }^{2}$ Eng. Agr., Dr., Departamento de Produção Vegetal, Universidade de São Paulo/Escola Superior de Agricultura "Luiz de Queiroz" (USP/ESALQ).
Avenida Pádua Dias, n.11, Caixa Postal 9, CEP 13418-900, Piracicaba, SP. E-mail: fggjunio@esalq.usp.br.

${ }^{3}$ Eng. Agr., Dr., Professor Titular, Departamento de Fitotecnia, Tecnologia de Alimentos e Sócio-Economia, UNESP - Campus de Ilha Solteira, Caixa postal 31, CEP 15385-000, Ilha Solteira, SP. 
was used with four replicates and factorially arranged treatments equivalent to $0,30,60,90$ and 120 $\mathrm{kg} . \mathrm{ha}^{-1}$ added nitrogen (as urea, containing $45 \%$ of $\mathrm{N}$ ) applied as a side dressing during the $\mathrm{V}_{4-3}$ and $\mathrm{V}_{4-6}$ phenological stage corresponding to the $3^{\text {rd }}$ and $6^{\text {th }}$ completely opened trifoliolate leaf on the main stem. Supplementation with up to $120 \mathrm{~kg} \cdot \mathrm{ha}^{-1}$ nitrogen promoted a greater increase in crude protein at $\mathrm{V}_{4-3}$ (unsupplemented $=17.6 \%$ and $16.3 \% ; 120 \mathrm{~kg}^{-h^{-1}} \mathrm{~N}=24.1 \%$ and $22.3 \%$ for cv. IPR Juriti and Pérola, respectively) than at $\mathrm{V}_{4-6}$ (unsupplemented $=19.2 \%$ and $18.3 \% ; 120 \mathrm{~kg}^{-h^{-1}} \mathrm{~N}=21.3 \%$ and $20.3 \%$ for $\mathrm{cv}$. IPR Juriti and Pérola, respectively). About $90 \%$ of the crude protein from cv. IPR Juriti was composed of soluble protein compared to $72 \%$ for the cv. Pérola. Albumins and globulins represented about $80 \%$ of the soluble protein and prolamins were lower at $0.6 \%$. In conclusion, nitrogen fertilization up to $120 \mathrm{~kg} \cdot \mathrm{ha}^{-1}$ applied as a side dressing at the $\mathrm{V}_{4-3}$ phenological stage in notillage under a thick mulch of millet promoted a greater increase of crude protein in common bean seeds than at the $V_{4-6}$ stage. The highest accumulation of soluble protein occurred at $90 \mathrm{~kg}^{-\mathrm{ha}^{-1}}$ applied nitrogen without having a significant influence on the physiological quality of the seeds.

Index terms: albumins, glutelins, physiological quality, soluble protein.

\section{INTRODUÇÃO}

A qualidade da semente, caracterizada pelos atributos genético, físico, sanitário e fisiológico, é fundamental no processo de produção de qualquer espécie vegetal multiplicada por sementes. O componente fisiológico, que é influenciado pelo ambiente em que as sementes se formam (Vieira et al., 1993), pode ser modificado pela intervenção do homem, como por exemplo, a adubação. A disponibilidade de nutrientes influi na formação do embrião e dos órgãos de reserva, assim como na composição química da semente e, dessa forma, poderá, consequentemente, influenciar o seu vigor e a sua qualidade (Sá, 1994). Os efeitos do nitrogênio $(\mathrm{N})$ sobre a qualidade fisiológica das sementes variam com as condições ambientais e o estádio de desenvolvimento da planta em que ocorre a aplicação do fertilizante (Carvalho e Nakagawa, 2000). No caso do feijoeiro, o fornecimento de $\mathrm{N}$ na semeadura e em cobertura é indispensável para o adequado desenvolvimento das plântulas e para a produção de sementes com alta qualidade. Também, segundo Teixeira et al. (2000), a adubação do feijoeiro com fertilizantes nitrogenados pode aumentar a produção de sementes, em consequência do incremento nos componentes de produtividade, tais como número de vagens por planta, número de sementes por vagem e massa de cem sementes.

A adubação nitrogenada altera a quantidade e qualidade do $\mathrm{N}$ presente na planta, aumentando os níveis de $\mathrm{N}$ solúvel, particularmente aminoácidos livres (Mattson, 1980). Nas sementes, a fração $\mathrm{N}$ não protéica é constituída principalmente por aminoácidos livres e pequenos peptídeos, que podem ocorrer devido a resíduos da síntese incompleta de proteínas ou como resultado de degradação deste composto (Smith e Circle, 1978 citados por Carelli et al., 1981). Estudando os efeitos das doses de 40 e 80 kg.ha-1 de N, Gomes Junior et al. (2005) observaram teor médio de proteína solúvel na semente de feijão de $14,4 \%$ e $16,3 \%$, contra $20,1 \%$ e $21,4 \%$ para a proteína bruta, indicando que grande parte do $\mathrm{N}$ contido na semente não participa da composição das proteínas, apresentando-se, possivelmente, na forma de aminoácidos livres e até mesmo como outros compostos não protéicos da semente.

As variações no teor de proteína bruta em sementes de feijão encontradas na literatura situam-se na faixa de $25,1 \%$ a $30,2 \%$ (Maldonado e Sammám, 2000) e de 20,4\% a $24,1 \%$ (Bordin et al., 2003); entre as principais frações solúveis, as globulinas e as albuminas representam, em média, $75 \%$ do total, sendo que a proporção entre essas duas frações varia de acordo com a variedade cultivada e a qualidade protéica está relacionada ao teor relativo de cada uma delas (Lajolo et al., 1996). Em algumas situações, tem sido observada relação positiva entre a adubação nitrogenada e o acúmulo de proteínas na semente de feijão; plantas adubadas com altas doses de $\mathrm{N}$ produziram sementes com maior teor de proteínas em relação às plantas adubadas com baixas doses deste nutriente (Patroni et al., 2002; Bordin et al., 2003; Gomes Junior et al., 2005).

As relações entre a aplicação de $\mathrm{N}$ em cobertura e o potencial fisiológico de sementes de feijão tem sido frequentemente estudadas por vários pesquisadores 
(Ambrosano et al., 1999; Bassan et al., 2001; Crusciol et al., 2003; Farinelli et al., 2006; Kikuti et al., 2007). A aplicação das doses de 0, 12,5 e $25 \mathrm{~kg} \cdot \mathrm{ha}^{-1}$ de $\mathrm{N}$ na semeadura e em cobertura no estádio fenológico $V_{4-5}$ (Crusciol et al., 2003) não influenciou a germinação e o vigor, avaliado pela primeira contagem de germinação, velocidade de germinação e condutividade elétrica. Por outro lado, Farinelli et al. (2006) observaram aumento da germinação e do vigor (teste de envelhecimento acelerado) com a aplicação das doses de 0,30,60 e $90 \mathrm{~kg} \cdot \mathrm{ha}^{-1}$ de N no estádio fenológico $\mathrm{V}_{4}$. Alto vigor de sementes de feijão em função da aplicação de até $210 \mathrm{~kg} \cdot \mathrm{ha}^{-1}$ de N, avaliado pelos testes de envelhecimento acelerado, de imersão em água e de condutividade elétrica também foi observado por Kikuti et al. (2007), porém sem ocorrerem efeitos sobre a germinação. Como se observa, os resultados com relação à aplicação de $\mathrm{N}$ sobre a qualidade de sementes de feijão ainda se mostram contraditórios, de forma que mais estudos sobre o assunto necessitam ser realizados, principalmente quando se trata do sistema de plantio direto.

No sistema de plantio direto, podem ocorrer modificações na dinâmica do $\mathrm{N}$ no solo, decorrente da ação de fatores bióticos e abióticos, alterando os processos do seu aproveitamento pelas plantas, de maneira diferenciada em relação ao sistema convencional. $\mathrm{O} \mathrm{N}$ absorvido pelas plantas combina com esqueletos carbônicos para a produção de aminoácidos, os quais resultam em proteínas que ficam armazenadas nos tecidos vegetais; na fase de enchimento de grãos estas reservas são quebradas, translocadas e armazenadas nestes órgãos, na forma de proteínas e aminoácidos (Marschner, 1995). Assim, alterações na dinâmica do $\mathrm{N}$ no solo podem modificar o metabolismo de aproveitamento pelas plantas e, ainda, indisponibilizar o nutriente na fase de maior exigência.

O objetivo neste trabalho foi avaliar o efeito da adubação nitrogenada em cobertura sobre o teor de proteína e o potencial fisiológico de sementes de feijão produzidas em sistema de plantio direto.

\section{MATERIAL E MÉTODOS}

A pesquisa foi realizada nos Laboratórios de Análise de Sementes e de Genética de Populações do Departamento de Fitotecnia, Tecnologia de Alimentos e Sócio-Economia da Faculdade de Engenharia de Ilha Solteira, Universidade Estadual Paulista "Júlio de Mesquita Filho" (UNESP).

Sementes de feijão das cultivares (cv.) IPR Juriti e
'Pérola' foram produzidas na estação de outono-inverno do ano agrícola de 2004/2005, no sistema de plantio direto sobre resíduos vegetais de milheto (Pennisetum americanum), 21,2 t.ha- ${ }^{-1}$ de biomassa seca. A análise química do solo, antes da semeadura do milheto, foi realizada pelo método de Raij e Quaggio (1983) e os resultados são apresentados a seguir: matéria orgânica, 29,0 g.dm ${ }^{-3} ; \mathrm{pH}\left(\mathrm{CaCl}_{2}\right)$, 5,4; P (resina), 12,0 mg.dm ${ }^{-3} ; \mathrm{K}$, $\mathrm{Ca}, \mathrm{Mg}, \mathrm{H}+\mathrm{Al}, \mathrm{SB}$ e CTC, 3,2, 21,0, 12,0, 31,0, 36,2 e $67,2 \mathrm{mmol} \cdot \mathrm{dm}^{-3}$, respectivamente, e saturação por bases, $54,0 \%$.

Por ocasião da semeadura do feijão, foram aplicados $250 \mathrm{~kg} \cdot \mathrm{ha}^{-1}$ da fórmula 04-30-10 e, quando as plantas se mostravam com o terceiro trifólio da haste principal totalmente expandido (estádio fenológico $\mathrm{V}_{4-3}$ segundo Fernandez et al., 1992), foram aplicadas, de uma única vez, as doses de 30, 60, 90 e $120 \mathrm{~kg} \cdot \mathrm{ha}^{-1}$ de $\mathrm{N}$ em cobertura, além da testemunha sem aplicação da uréia. As mesmas doses do fertilizante nitrogenado também foram aplicadas no estádio $\mathrm{V}_{4-6}$, correspondente à presença da sexta folha da haste principal das plantas completamente expandida. Assim, para cada cultivar foi utilizado o delineamento em blocos casualisados, com quatro repetições e arranjo fatorial $5 \times 2$ envolvendo cinco doses de $\mathrm{N}$ e duas épocas de aplicação do $\mathrm{N}$ em cobertura.

As proteínas de reserva albuminas, globulinas, prolaminas e glutelinas foram extraídas de acordo com a sua solubilidade pelo método descrito por Sturgis et al. (1952), modificado de acordo com Garcia-Agustin e PrimoMillo (1989). Para cada tratamento, três amostras de 0,5 g de sementes, previamente moídas em moinho tipo Wiley com malha de $1 \mathrm{~mm}$, foram homogeneizados com $10 \mathrm{~mL}$ de água destilada em um homogeneizador Superohm (tipo Polytron) gerado na máxima velocidade, por 15 segundos. A seguir, os homogeneizados foram submetidos às extrações consecutivas em água destilada (albuminas), cloreto de sódio $5 \%(\mathrm{~m} / \mathrm{v})$ (globulinas), etanol $60 \%(\mathrm{v} / \mathrm{v})$ (prolaminas) e hidróxido de sódio $0,4 \%(\mathrm{~m} / \mathrm{v})$ (glutelinas). Os extratos foram centrifugados a $2500 \mathrm{rpm}$, durante 20 minutos, a $4{ }^{\circ} \mathrm{C}$ e os sobrenadantes foram filtrados. Alíquotas de cada extrato foram utilizadas para determinações de proteínas, segundo o método de Lowry (Lowry et al., 1951), utilizando-se de albumina de soro bovino como padrão.

O teor de proteína bruta foi determinado pela decomposição das proteínas e outros componentes nitrogenados na presença de $\mathrm{H}_{2} \mathrm{SO}_{4}$ concentrado a quente, segundo o método Semimicro-Kjeldahl, multiplicando-se o valor do $\mathrm{N}$ total pelo fator 6,25 (AOAC, 1995). Todas as 
determinações do teor de proteína total foram realizadas em duplicata.

A germinação foi avaliada utilizando quatro repetições de 50 sementes por tratamento, as quais foram distribuídas sobre duas folhas de papel toalha para germinação e cobertas com uma terceira, previamente umedecidas com quantidade de água equivalente a 2,5 vezes a sua massa seca. Os rolos contendo as sementes foram colocados em germinador a 25 ${ }^{\circ} \mathrm{C}$. No quinto dia após a instalação do teste foi realizada a primeira contagem da germinação, computando-se as plântulas normais e, ao final do teste, foi calculado o índice de velocidade de germinação segundo a fórmula proposta por Maguire (1962). O índice foi obtido a partir de contagens diárias das plântulas normais.

$\mathrm{O}$ teste de envelhecimento acelerado foi realizado com quatro repetições de 50 sementes para cada tratamento, colocando-se 220 sementes sobre uma tela de inox ajustada dentro de uma caixa de plástico, contendo no fundo $40 \mathrm{~mL}$ de água. Após a colocação da tampa, a caixa foi levada ao germinador regulado à temperatura de $42{ }^{\circ} \mathrm{C}$, onde permaneceu por 60 horas. Transcorrido esse período, as sementes foram semeadas conforme descrito para o teste de germinação e as plântulas normais foram avaliadas cinco dias após a instalação do teste.

A emergência de plântula foi avaliada em campo. Foram semeadas quatro repetições de 50 sementes por tratamento, distribuídas em sulcos de $2 \mathrm{~m}$ de comprimento e $5 \mathrm{~cm}$ de profundidade. Os sulcos foram espaçados de $40 \mathrm{~cm}$ e as contagens foram realizadas aos 15 dias após a semeadura, computando-se as plântulas com os cotilédones acima da superfície do solo e as folhas originárias do embrião (folhas simples) com as margens não mais se tocando.

Os dados foram submetidos à análise da variância, sendo os efeitos de épocas comparadas pelo teste F. O efeito das doses de $\mathrm{N}$ foi avaliado por meio de análise de regressão polinomial.

\section{RESULTADOS E DISCUSSÃO}

Para a cv. IPR Juriti, interações significativas foram observadas nas avaliações de albuminas, globulinas, glutelinas e proteína bruta. Para a cv. Pérola, além destas quatro avaliações, as interações também ocorreram para a proteína solúvel total e emergência de plântula. Nas avaliações de proteína solúvel total, de germinação, de primeira contagem de germinação e de velocidade de germinação para a cv. IPR Juriti foram observados efeitos significativos apenas das doses de $\mathrm{N}$. Verificou-se, também, efeito significativo apenas de época de aplicação de N, para o teor de prolaminas da semente das duas cultivares e para o teste de envelhecimento acelerado da cv. IPR Juriti. As avaliações de emergência de plântula da cv. IPR Juriti, de germinação, de primeira contagem de germinação, de velocidade de germinação e de envelhecimento acelerado da cv. Pérola não foram influenciadas pelas doses ou épocas de aplicação de $\mathrm{N}$, cujos valores médios foram $87 \%, 90 \%$, $82 \%, 8,7$ e $88 \%$, respectivamente.

\section{Teor de proteína das sementes}

$\mathrm{O}$ acúmulo de albuminas na semente da cv. IPR Juriti apresentou resposta quadrática em função das doses de $\mathrm{N}$ aplicadas no estádio fenológico $\mathrm{V}_{4-6}$ (Figura 1). Pela equação ajustada, o maior acúmulo de albuminas na semente seria obtido com a aplicação da dose de $59 \mathrm{~kg} \cdot \mathrm{ha}^{-1}$. Para esta fração protéica o percentual máximo obtido no estádio fenológico $\mathrm{V}_{4-6}$ foi próximo do valor médio observado para o estádio fenológico $\mathrm{V}_{4-3}, 5,4 \%$.

Com relação ao acúmulo de globulinas, foi observada resposta quadrática em função da aplicação do $\mathrm{N}$ nos estádios $\mathrm{V}_{4-3}$ e $\mathrm{V}_{4-6}$ (Figura 1); quando a adubação foi realizada no estádio $\mathrm{V}_{4-3}$ a equação ajustada evidenciou menor acúmulo de globulinas com a aplicação da dose de $53 \mathrm{~kg} \cdot \mathrm{ha}^{-1}$, entretanto, foi observado acúmulo significativo à medida que se aumentou a dose, com o máximo teor $(2,7 \%)$, obtido em função da aplicação de $120 \mathrm{~kg} \cdot \mathrm{ha}^{-1}$. A presença de resíduos culturais com alta relação $\mathrm{C} / \mathrm{N}$, antes da semeadura de uma cultura, possibilita o consumo de $\mathrm{N}$ pela biomassa microbiana do solo, imobilizando-o na sua massa celular, podendo causar deficiências na cultura em desenvolvimento (Sá, 1999). Assim, devido à alta relação $\mathrm{C} / \mathrm{N}$ dos resíduos de milheto, é possível que o $\mathrm{N}$ proveniente de doses menores tenha sido consumido pela biomassa microbiana e mineralizado tardiamente, após o período de maior exigência, quando o aproveitamento pelas plantas era baixo; talvez esta seja a razão para o baixo acúmulo de globulinas na semente. No caso das doses maiores, mesmo que a imobilização microbiana tenha ocorrido, supõe-se que tenha tido $\mathrm{N}$ suficiente para nutrir as plantas adequadamente, propiciando alto teor de globulinas na semente. Quanto à aplicação do $\mathrm{N}$ no estádio $\mathrm{V}_{4-6}$, foi observado que o máximo teor seria obtido com a aplicação de $78 \mathrm{~kg} \cdot \mathrm{ha}^{-1}$.

Resposta quadrática à aplicação do $\mathrm{N}$ no estádio $\mathrm{V}_{4-3}$ também foi observada para o teor de glutelinas (Figura 1), obtendo-se, com base na equação, o máximo acúmulo com a aplicação da dose de $71 \mathrm{~kg} \cdot \mathrm{ha}^{-1}$. Já, quanto às prolaminas (Figura 1), o maior teor foi observado nas sementes cujas plantas receberam adubação nitrogenada no estádio $\mathrm{V}_{4-3} \mathrm{em}$ relação ao estádio $\mathrm{V}_{4-6}$, com percentuais de $0,7 \%$ e $0,6 \%$, respectivamente. 

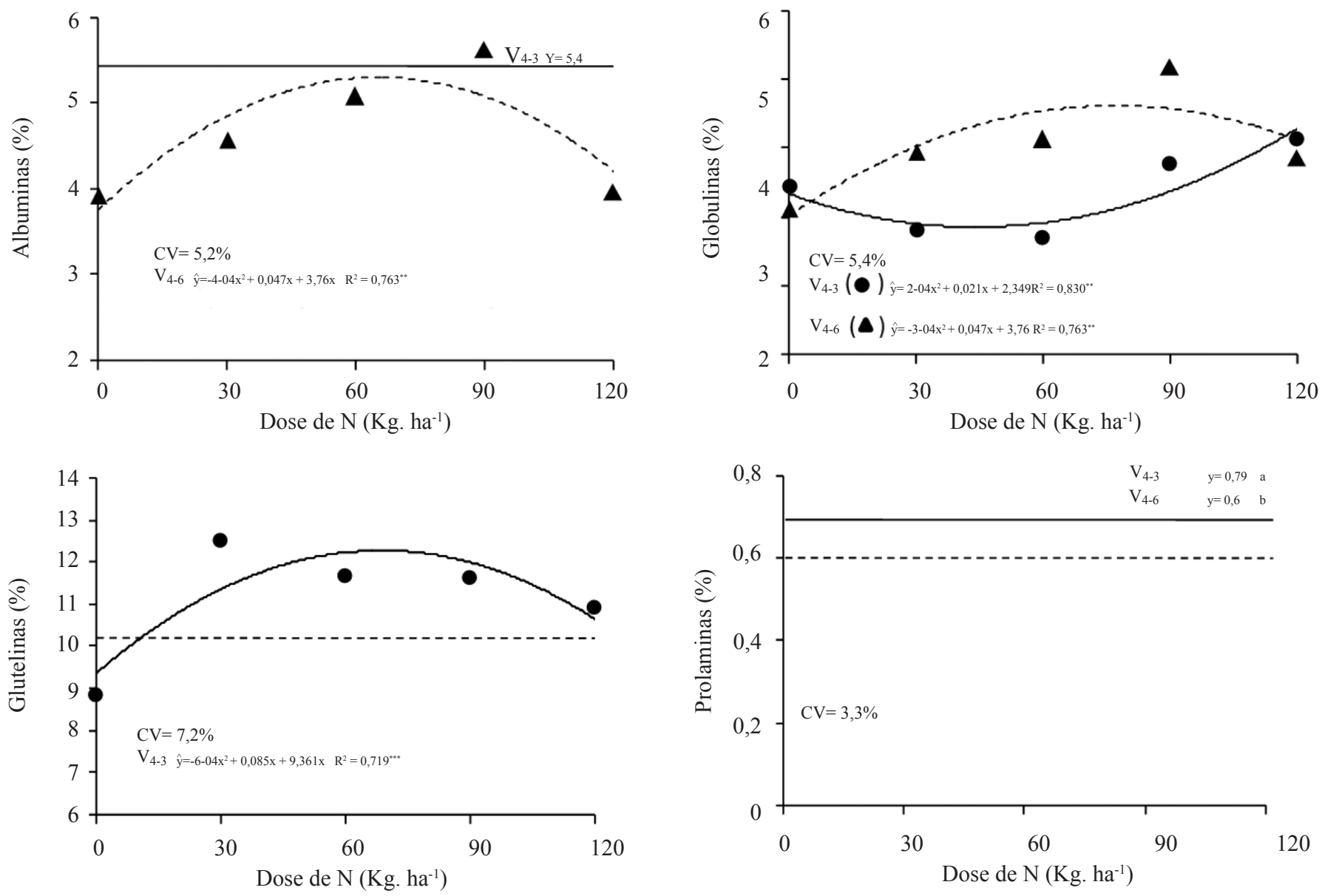

Médias da variável resposta prolaminas, seguidas por letras distintas, diferem entre si pelo teste $\mathrm{F}$.

FIGURA 1. Frações protéicas albuminas, globulinas, glutelinas e prolaminas da semente de feijão cv. 'IPR Juriti', em função da aplicação de doses de nitrogênio no estádio fenológico $V_{4}$, em sistema de plantio direto.

Embora não tenha sido observado efeito isolado das épocas de adubação para o teor total de proteína solúvel da semente da cv. IPR Juriti (Figura 2), os dados médios de épocas em função das doses de $\mathrm{N}$ se ajustaram a uma equação quadrática, sendo que, com base na equação, o máximo teor seria obtido com a aplicação de $84 \mathrm{~kg} \cdot h \mathrm{~h}^{-1}$ de $\mathrm{N}$. $\mathrm{O}$ acúmulo de proteína bruta na semente apresentou resposta quadrática às doses de $\mathrm{N}$, porém, as doses que possibilitaram maiores acúmulos em cada época foram diferentes. Observase que na medida em que a aplicação foi realizada mais tardiamente (estádio $\mathrm{V}_{4-6}$ ), houve tendência de redução da dose responsável pelo maior acúmulo de proteína bruta na semente. Com base na equação, o máximo acúmulo de proteína bruta com adubação no estádio $\mathrm{V}_{4-3}$ seria obtido com a aplicação de $195 \mathrm{~kg} \cdot \mathrm{ha}^{-1}$, fora, portanto, do espaço experimental do estudo; entretanto, com a aplicação da dose de $120 \mathrm{~kg} \cdot \mathrm{ha}^{-1}$ o teor seria de $24,1 \%$, superior ao máximo acúmulo correspondente ao estádio $\mathrm{V}_{4-6}(22,9 \%)$ que seria obtido aplicando-se $73 \mathrm{~kg} \cdot \mathrm{ha}^{-1}$ de N.

$\mathrm{O}$ efeito das doses de $\mathrm{N}$ aplicadas no estádio $\mathrm{V}_{4-6}$ apresentou resposta quadrática para o teor de albuminas na semente da cv. Pérola (Figura 3), de maneira similar ao observado na cv. IPR Juriti; entretanto, para o estádio $\mathrm{V}_{4-3}$, embora também tenha ocorrido resposta quadrática, o comportamento da curva foi inverso ao observado para o estádio $\mathrm{V}_{4-6}$. Com base na equação correspondente a este estádio, se teria o máximo acúmulo de albuminas com a aplicação de $90 \mathrm{~kg} \cdot \mathrm{ha}^{-1}$ de $\mathrm{N}$, ao passo que, para o estádio $\mathrm{V}_{4-3}$ o menor teor $(2,4 \%)$ seria obtido com a aplicação de 74 kg.ha- ${ }^{-1}$ de N. Ressalta-se, entretanto, que a dose de máximo acúmulo aplicada no estádio $\mathrm{V}_{4-6}$ foi maior que a obtida para a cv. IPR Juriti, 59 kg.ha ${ }^{-1}$. 

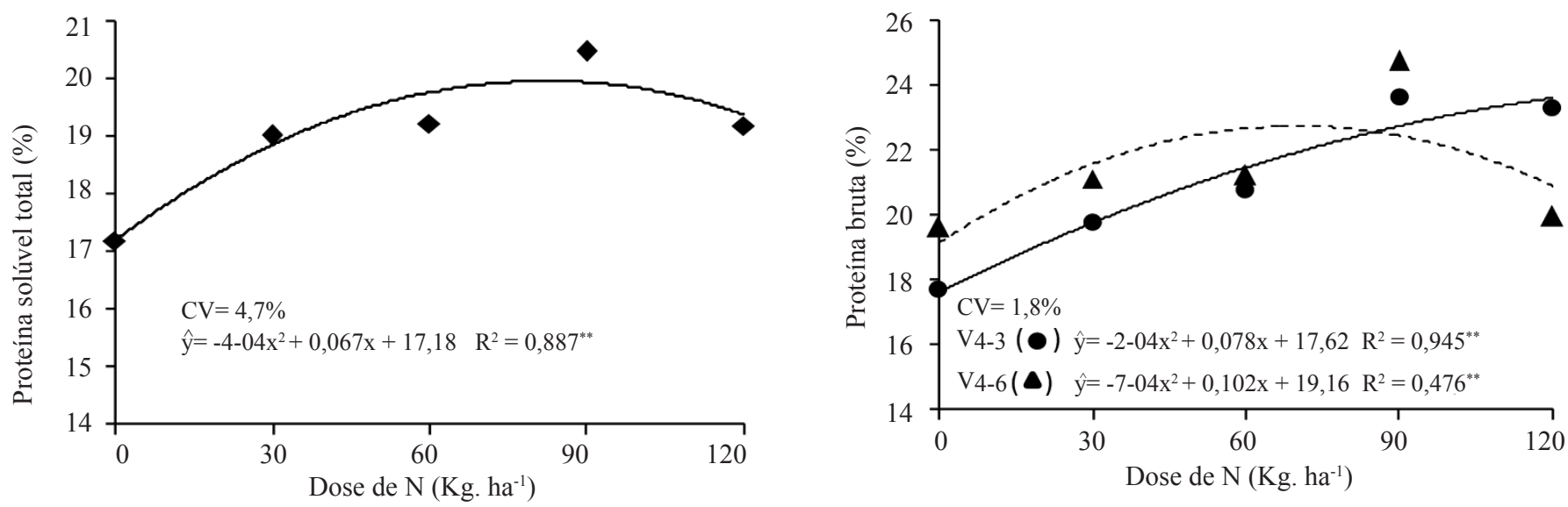

FIGURA 2. Teor de proteína solúvel (médias dos estádios $V_{4-3}$ e $V_{4-6}$ ) e de proteína bruta da semente de feijão cv. IPR Juriti, em função da aplicação de doses de nitrogênio no estádio fenológico $V_{4}$, em sistema de plantio direto.
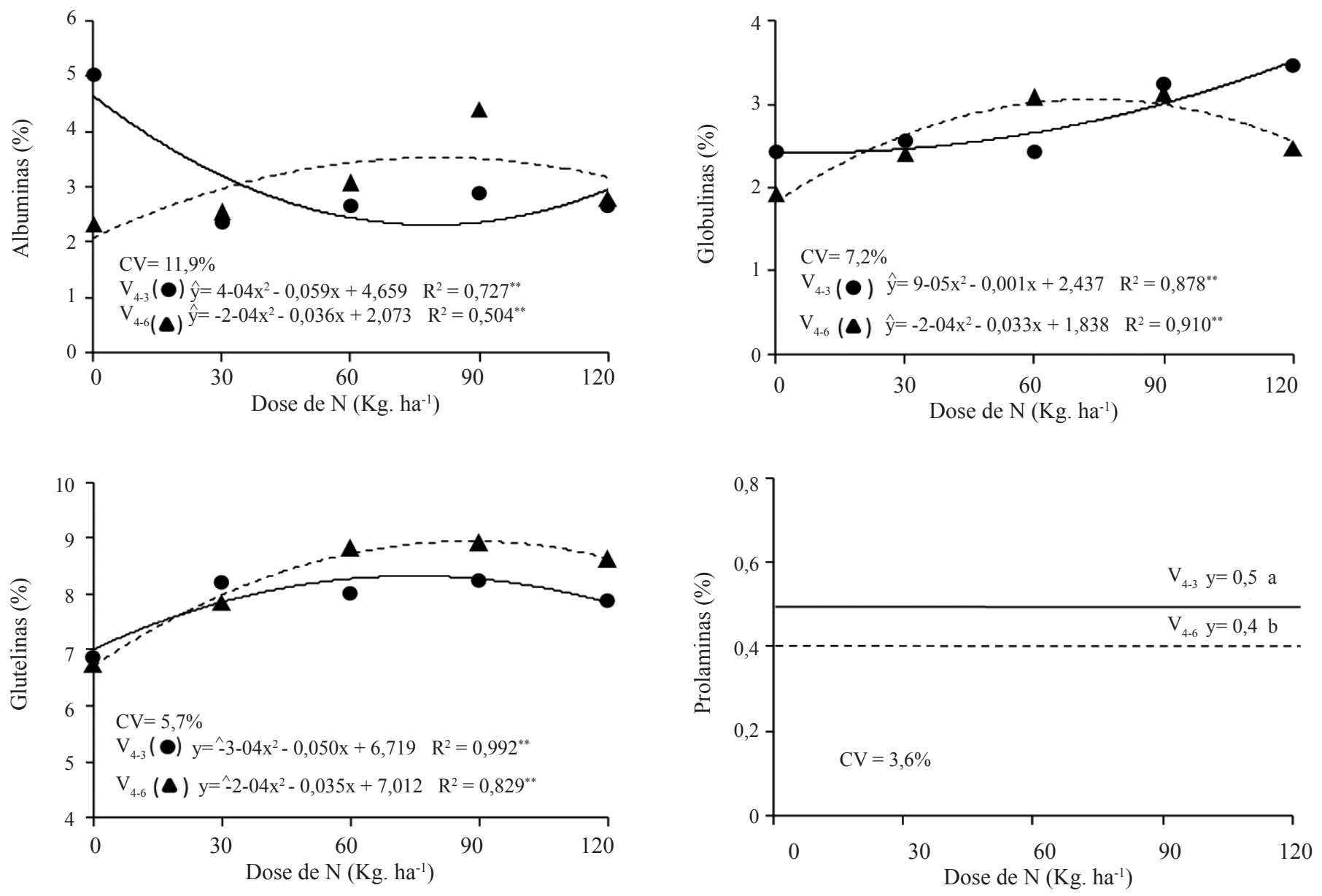

Médias da variável resposta prolaminas, seguidas por letras distintas, diferem entre si pelo teste F.

FIGURA 3. Frações protéicas albuminas, globulinas, glutelinas e prolaminas da semente de feijão cv. Pérola, em função da aplicação de doses de nitrogênio no estádio fenológico $V_{4}$, em sistema de plantio direto. 
Os dados do teor de globulinas em função das doses aplicadas na cv. Pérola, nas duas épocas, se ajustaram a equações do segundo grau (Figura 3), sendo, para o estádio $\mathrm{V}_{4-6}$, observado o mesmo tipo de resposta obtido para a cv. IPR Juriti, ou seja, máximo acúmulo próximo da dose de $90 \mathrm{~kg} \cdot \mathrm{ha}^{-1}$ aplicada no estádio $\mathrm{V}_{4-6}$. Já, para o estádio $\mathrm{V}_{4-3}$, de maneira similar ao observado para a cv. IPR Juriti, foi observado acúmulo significativo à medida que se aumentou a dose de N, com o máximo teor $(3,6 \%)$, obtido em função da aplicação de $120 \mathrm{~kg} \cdot \mathrm{ha}^{-1}$. Quanto ao teor de glutelinas (Figura 3), as curvas de resposta ao $\mathrm{N}$ foram semelhantes nas duas épocas, sendo os maiores acúmulos obtidos em doses próximas, 83 e $88 \mathrm{~kg} \cdot$ ha $^{-1}$ para os estádios $\mathrm{V}_{4-3} \mathrm{e} \mathrm{V}_{4-6}$. Assim como observado para a cv. IPR Juriti, o teor de prolaminas da semente da cv. Pérola, cujas plantas receberam a aplicação de $\mathrm{N}$ no estádio $\mathrm{V}_{4-3}$, foi maior em relação ao estádio $\mathrm{V}_{4-6}$; observa-se na Figura 3 que os valores foram de 0,5\% e 0,4\%, respectivamente.

O teor de proteína total solúvel na semente da cv. Pérola apresentou resposta linear à aplicação das doses de $\mathrm{N}$ no estádio $\mathrm{V}_{4-3}$ (Figura 4). Pela equação ajustada, quando foi aplicada a dose máxima de $120 \mathrm{~kg} \cdot \mathrm{ha}^{-1} \mathrm{o}$ teor de proteínas foi de $15,3 \%$, máximo teor obtido com a aplicação da dose de $75 \mathrm{~kg} \cdot \mathrm{ha}^{-1}$ a partir da equação relativa ao estádio $\mathrm{V}_{4-6}$ (neste caso, resposta quadrática). Substituindo-se o valor de $75 \mathrm{~kg} \cdot \mathrm{ha}^{-1}$ na equação correspondente ao estádio $\mathrm{V}_{4-3}$ se teria acúmulo de $14,8 \%$ de proteína solúvel. Com relação ao teor de proteína bruta os dados referentes ao estádio $\mathrm{V}_{4-3}$ se ajustaram em uma regressão linear, sendo observado acúmulo de 22,9\% com a aplicação da dose de 120 kg.ha-1, fora, portanto, do espaço experimental do estudo. Resposta quadrática foi observada para o estádio $\mathrm{V}_{4-6}$, com o máximo acúmulo (20,6\%), obtido com a aplicação de $88 \mathrm{~kg} \cdot \mathrm{ha}^{-1}$ de $\mathrm{N}$. Esses resultados evidenciam que quando a aplicação do $\mathrm{N}$ é realizada em estádios avançados do desenvolvimento do feijoeiro, o acúmulo de proteínas na semente fica limitado a doses menores, em relação à adubação em estádios inicias do desenvolvimento. Considerando a imobilização microbiana, possivelmente pelo fato do $\mathrm{N}$ ter sido aplicado mais tardiamente, o aproveitamento de parte do nutriente proveniente das doses maiores pode não ter ocorrido em tempo hábil se ser acumulado nas sementes.
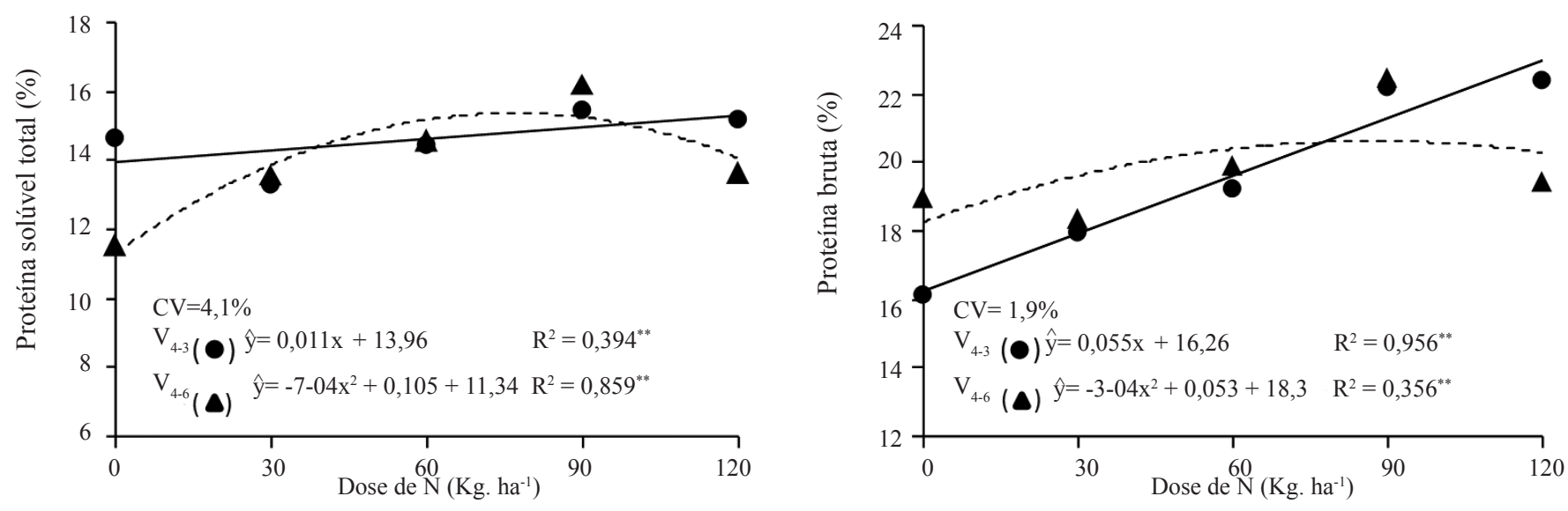

FIGURA 4. Teor de proteína solúvel e de proteína bruta da semente de feijão cv. Pérola, em função da aplicação de doses de nitrogênio no estádio fenológico $\mathrm{V}_{4}$, em sistema de plantio direto.

Analisando as Figuras 1 e 3, observa-se que as albuminas e as glutelinas representaram as maiores frações protéicas na semente de feijão, com aproximadamente $80 \%$ do teor de proteína solúvel total e as prolaminas a menor fração. Entretanto, estes resultados discordaram das informações da literatura de que, em média, $75 \%$ da proteína solúvel total da semente do feijoeiro é representada pelas globulinas e albuminas (Lajolo et al., 1996). Neste trabalho somente a fração glutelinas correspondeu a mais da metade da proteína total solúvel das sementes.

No geral, as doses ótimas para obtenção de máximo acúmulo de proteína solúvel na semente, independente da cultivar, ficaram entre 70 e $90 \mathrm{~kg} \cdot \mathrm{ha}^{-1}$ de N (Figuras 2 e 4). Estes resultados corroboram com os observados por Gomes Junior et al. (2005) que encontraram maior teor de proteína solúvel na semente de feijão da cv. IAC Carioca 
com a aplicação de 80 kg.ha ${ }^{-1}$ de $\mathrm{N}(16,3 \%)$ em relação à dose de $40 \mathrm{~kg} \cdot \mathrm{ha}^{-1}(14,4 \%)$. Nesta pesquisa, respostas a doses maiores do que estas ocorreram apenas para o teor de proteína bruta (Figuras 2 e 4), o que não representa eficiência do aproveitamento do nitrogênio. Devido ao ciclo curto do feijoeiro (90 a 100 dias), melhor aproveitamento do $\mathrm{N}$ é esperado nas fases iniciais do desenvolvimento vegetativo das plantas. Quando a adubação é realizada dentro do período vegetativo, porém mais tardiamente, pode ocorrer menor acúmulo de proteínas nas sementes, conforme foi observado para os teores de prolaminas em ambas as cultivares e para o teor de albuminas para a cv. IPR Juriti, aumentando o teor de compostos nitrogenados não protéicos. Esse tipo de resposta pode ser ainda mais evidente no sistema de plantio direto, onde, devido à imobilização microbiana, pode ocorrer deficiência de $\mathrm{N}$ na fase de maior exigência pelas plantas, o que possivelmente justifica os resultados obtidos neste trabalho.

O máximo teor de proteína bruta da semente das cvs. IPR Juriti e Pérola foi de $24,1 \%$ e $22,9 \%$, respectivamente. Estes valores foram próximos dos obtidos por Bordin et al. (2003), com variação de $20,4 \%$ a $24,1 \%$ em função das doses de 0 , 25,50 e $75 \mathrm{~kg} \mathrm{ha}^{-1}$ de N, porém superiores aos observados por Gomes Junior et al. (2005) na semente da cv. IAC Carioca, em média 20,8\%; e inferiores aos relatados por Maldonado e Sammám (2000) que encontraram variação do teor protéico de $25,1 \%$ a $30,2 \%$. Vários fatores podem influenciar o acúmulo de proteína nas sementes, podendo variar desde características intrínsecas da cultivar até variações edáficas da área de cultivo e atuação de fatores ambientais (Lajolo et al., 1996). Entretanto, a eficiência do aproveitamento do $\mathrm{N}$ pode ser determinada pela relação entre os teores de proteína solúvel e de proteína bruta da semente, visto que parte do $\mathrm{N}$ pode estar na forma de aminoácidos livres ou peptídeos que não compõem as proteínas (Smith e Circle, 1978 citados por Carelli et al., 1981). O teor de proteína solúvel correspondeu a cerca de $90 \%$ da proteína bruta da semente da cv. IPR Juriti, contra $72 \%$ da cv. Pérola, evidenciando diferenças na eficiência do aproveitamento do $\mathrm{N}$.

\section{Potencial fisiológico das sementes}

Os efeitos das doses de $\mathrm{N}$ foram pouco evidenciados nos resultados de avaliação do potencial fisiológico das sementes logo após a colheita. Para a cv. IPR Juriti a germinação diminuiu com o aumento da dose de N. Os dados médios das épocas de adubação evidenciaram decréscimo na primeira contagem de germinação, na germinação e na velocidade de germinação a partir da aplicação das doses de 90 e 120 kg.ha- ${ }^{-1}$ (Figura 5); entretanto, observa-se que a germinação mínima foi de $90 \%$, com redução de apenas $6 \%$ em relação à germinação máxima. Os resultados do teor de proteína total solúvel (Figura 2) indicaram máximo acúmulo nas sementes com a aplicação de $84 \mathrm{~kg} \cdot \mathrm{ha}^{-1}$ de $\mathrm{N}$, com redução do teor a partir da aplicação de doses maiores do que esta. Observando os resultados apresentados na Figura 5, pode-se inferir que a redução do potencial fisiológico das sementes foi devida ao menor acúmulo de proteínas solúveis nas sementes, tendo-se como respaldo as argumentações de Sá (1994).
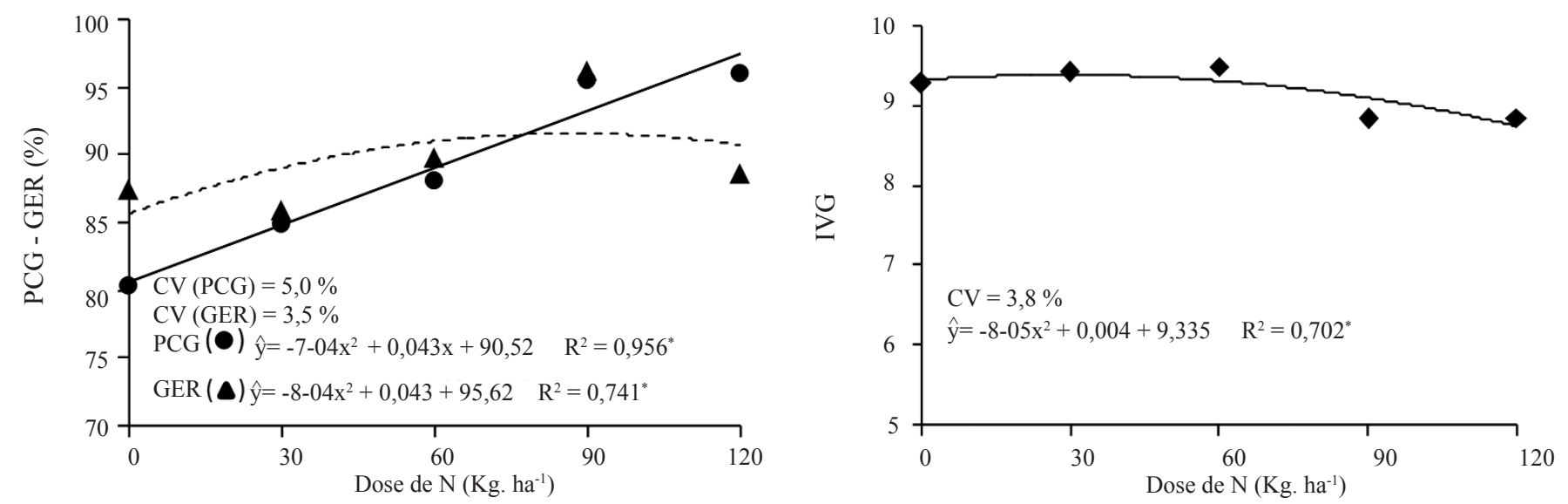

FIGURA 5. Primeira contagem de germinação (PCG), germinação (GER) e índice de velocidade de germinação (IVG) da semente de feijão cv. IPR Juriti, em função da aplicação de doses de nitrogênio no estádio fenológico $\mathrm{V}_{4}$, em sistema de plantio direto, Selvíria, MS, 2005 (médias dos estádios $\mathrm{V}_{4-3}$ e $\mathrm{V}_{4-6}$ ). 
Os resultados desta pesquisa discordam dos observados por Ambrosano et al. (1999), sem influência do N sobre a germinação, por Crusciol et al. (2003) e Kikuti et al. (2007), sem influência do $\mathrm{N}$ sobre a germinação e velocidade de germinação, por Farinelli et al. (2006), com o aumento da germinação até a dose de $160 \mathrm{~kg} \cdot \mathrm{ha}^{-1} \mathrm{e}$ por Bassan et al. (2001), com germinação acima de $90 \%$ com a aplicação de $\mathrm{N}$ em cobertura até a dose de $90 \mathrm{~kg} \cdot \mathrm{ha}^{-1}$, na ausência de adubação foliar com molibdênio.

Ainda com relação à cv. IPR Juriti, os resultados do teste de envelhecimento acelerado evidenciaram maior vigor das sementes oriundas de plantas que receberam aplicação de $\mathrm{N}$ no estádio $\mathrm{V}_{4-3}$ em relação ao estádio $\mathrm{V}_{4-6}$, de $89 \%$ e $77 \%$, respectivamente (Figura 6), porém sem ocorrerem influências das doses de $\mathrm{N}$, discordando dos resultados obtidos por Farinelli et al. (2006) e Kikuti et al. (2007), os quais aplicaram doses maiores, até 160 e 210 kg.ha- ${ }^{-1}$, respectivamente.

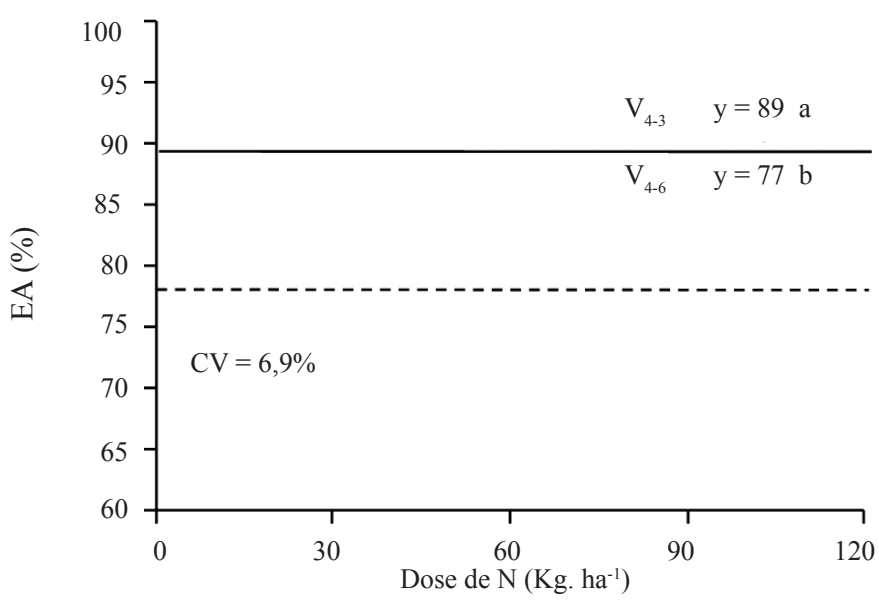

Médias seguidas por letras distintas diferem entre si pelo teste F.

FIGURA 6. Envelhecimento acelerado (EA) da semente de feijão cv. IPR Juriti, em função da aplicação de doses de nitrogênio no estádio fenológico $\mathrm{V}_{4}$, em sistema de plantio direto.

Foi observada resposta quadrática ao $\mathrm{N}$ aplicado nos estádios $\mathrm{V}_{4-3}$ e $\mathrm{V}_{4-6}$ para a emergência de plântulas da cV. Pérola (Figura 7), discordando dos resultados obtidos por Kikuti et al. (2007). Observa-se que as curvas apresentaram comportamento semelhante às correspondentes das avaliações do teor de albuminas e globulinas (Figura 3), indicando uma relação entre o acúmulo destas frações na semente e o desempenho em campo (positivo ou negativo), dependendo da época de aplicação do N. Pela equação correspondente ao estádio $\mathrm{V}_{4-6}$ (Figura 7), o maior percentual de emergência de plântulas seria obtido com a aplicação de $101 \mathrm{~kg} \cdot \mathrm{ha}^{-1}$ de N. Embora não tenha sido observado efeito das doses de $\mathrm{N}$ para todas as avaliações do potencial fisiológico das sementes, os resultados de emergência de plântulas obtidos para esta época apresentaram-se coerentes, visto que a dose responsável pelo máximo acúmulo de proteína na semente foi próxima daquela que proporcionou maior percentual de plântulas emersas no teste de emergência em campo.

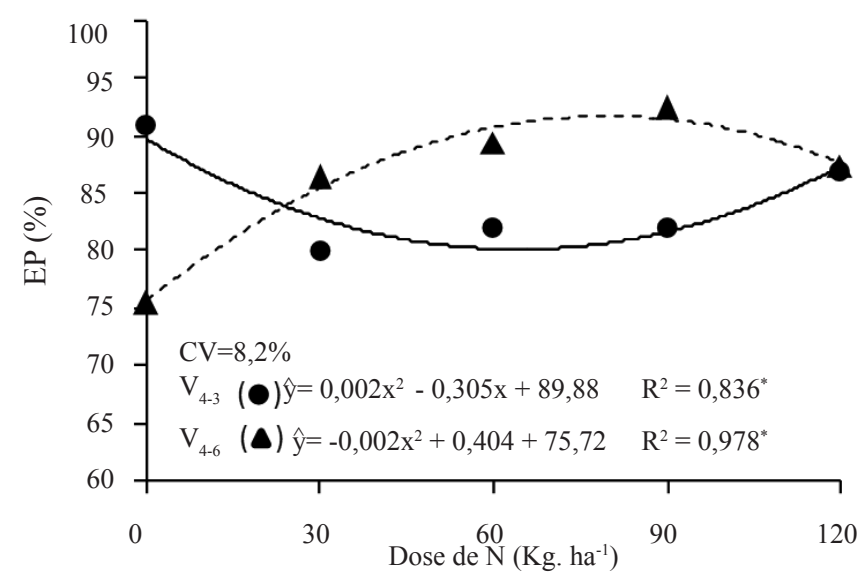

FIGURA 7. Emergência de plântula (EP) da semente de feijão cv. Pérola, em função da aplicação de doses de nitrogênio no estádio fenológico $V_{4}$, em sistema de plantio direto.

\section{CONCLUSÕES}

A aplicação de até $120 \mathrm{~kg} \cdot \mathrm{ha}^{-1}$ de $\mathrm{N}$ no estádio fenológico $\mathrm{V}_{4-3}$, em sistema de plantio direto sob densa quantidade de palha de milheto, propicia maior acúmulo de proteína bruta na semente de feijão em relação à aplicação no estádio $\mathrm{V}_{4-6}$.

A dose de $90 \mathrm{~kg} \cdot \mathrm{ha}^{-1}$ de $\mathrm{N}$ propicia maior acúmulo de proteína solúvel na semente, sem, contudo, exercer influência acentuada sobre o seu potencial fisiológico.

\section{AGRADECIMENTOS}

Os autores agradecem à Selma Maria Bozite de Moraes, pelo suporte técnico nas análises do teor de proteína, ao Dr. Miller B. Mcdonald, pela revisão do abstract e à Fundação de Amparo à Pesquisa do Estado de São Paulo (FAPESP), pelo financiamento da pesquisa (proc.: 2003/11880-0). 


\section{REFERÊNCIAS}

AMBROSANO, E.J.; AMBROSANO, G.M.B.; WUTKE, E.B.; BULISANI, E.A.; MARTINS, A.L.M.; SILVEIRA, L.C.P.Efeitos da adubação nitrogenada e com micronutrientes na qualidade de sementes do feijoeiro cultivar IAC - Carioca. Bragantia, v.58, n.2, p.393-399, 1999.

ASSOCIATION OF OFFICIAL ANALYTICAL CHEMISTS - AOAC. 1995. Official Methods of Analysis. 16.ed. Washington: AOAC, 1995.

BASSAN, D.A.Z.; ARF, O.; BUZETTI, S.; CARVALHO, M.A.C.; SANTOS, N.C.B.; SÁ, M.E. Inoculação de sementes e aplicação de nitrogênio e molibdênio na cultura do feijão de inverno: produção e qualidade fisiológica de sementes. Revista Brasileira de Sementes, v.23, n.1, p.76-83, 2001.

BORDIN, L.; FARINELLI, R.; PENARIOL, F.G.; FORNASIERI FILHO, D. Sucessão de cultivo de feijãoarroz com doses de adubação nitrogenada após adubação verde, em semeadura direta. Bragantia, v.62, n.3, p.417428, 2003.

CARELLI, M.L.C.; FAHL, J.I.; TEIXEIRA, J.P.F. Efeito do nitrogênio no teor de proteína e composição em aminoácidos de sementes de feijão. Pesquisa Agropecuária Brasileira, v.16, n.6, p.795-799, 1981.

CARVALHO, N.M.; NAKAGAWA, J. Sementes: ciência, tecnologia e produção. Jaboticabal: FUNEP, 2000. 588p.

CRUSCIOL, C.A.C.; LIMA, E.D.; ANDREOTTI, M.; NAKAGAWA, J.; LEMOS, L.B.; MARUBAYASHI, O.M. Efeito do nitrogênio sobre a qualidade fisiológica, produtividade e características de sementes de feijão. Revista Brasileira de Sementes, v.25, n.1, p.108-115, 2003.

FARINELLI, R.; LEMOS, L.B.; CAVARIANI, C.; NAKAGAWA, J. Produtividade e qualidade fisiológica de sementes de feijão em função de sistemas de manejo de solo e adubação nitrogenada. Revista Brasileira de Sementes, v.28, n.2, p.102-109, 2006.

FERNANDEZ, F.; GEPTS, P.; LOPEZ, B.N. Etapas de desenvolvimento da planta de feijão. In: EMPRESA DE PESQUISA AGROPECUÁRIA E DIFUSÃO DE TECNOLOGIA DE SANTA CATARINA. A cultura do feijão em Santa Catarina. Florianópolis: EPAGRI, 1992. p.53-73.

GARCIA-AGUSTIN, P.; PRIMO-MILLO, E. Ultrastructural and biochemical changes in cotyledon reserve tissues during germination of citrus seeds. Journal of Experimental Botany, v.40, p.383-390, 1989.
GOMES JUNIOR, F.G.; LIMA, E.R.; LEAL, A.J.F.; MATOS, F.A.; SÁ, M.E.de; HAGA, K.I. Teor de proteína em grãos de feijão em diferentes épocas e doses de cobertura nitrogenada. Acta Scientiarum, v.27, n.3, p.455-459, 2005.

KIKUTI, H.; KIKUTI, A.L.P.; ANDRADE, M.J.B.; PEREIRA, C.E.; VON PINHO, E.V.R. Potencial fisiológico de sementes de feijoeiro em função de nitrogênio e fósforo. Revista de Agricultura, v.82, p.215-222, 2007.

LAJOLO, F.M.; GENOVESE, M.I.; MENEZES, E.W. Qualidade nutricional. In: ARAÚJO, R.S.; RAVA, C.A.; STONE, L.F.; ZIMMERMANN, M.J.O. (Coord.). Cultura do feijoeiro comum no Brasil. Piracicaba: Associação Brasileira para Pesquisa da Potassa e do Fosfato, 1996. p.2356.

LOWRY, O.H.; ROSEBROUGH, N.J.; FARR, A.L.; RANDALL, R.J. Protein measurement with the Folin phenol reagent. Journal of Biological Chemistry, v.193, p.265$275,1951$.

MAGUIRE, J.D. Speed of germination-aid in selection and evaluation for seedling emergence and vigour. Crop Science, v.2, n.2, p.176-177, 1962.

MALDONADO, S.; SAMMÁM, N. Composición química y contenido de minerales de leguminosas y cereales producidos en el noroeste argentino. Archivos Latino Americanos de Nutrición, v.50, n.2, p.195-199, 2000.

MARSCHNER, H. Mineral nutrition of higher plant. 2.ed. New York: Academic Press, 1995. 889p.

MATTSON, W.J. Herbivory in relation to plant nitrogen content. Annual Review of Ecology and systematics, v.11, p.119-161, 1980.

PATRONI, S.M.S.; ANDRADE, C.A.B.; JACINTO, D.M.; CLEMENTE, E.; BISO, J.C.; SCAPIM, C.A. Avaliação de diferentes níveis de adubação em três cultivares de feijão carioca. 2-Qualidade nutricional dos grãos. In: REUNIÃ̃O NACIONAL DE PESQUISA DE FEIJÃO, 7., 2002, Viçosa. Resumos... Viçosa: UFV, 2002. p.541-543.

RAIJ, B. Van; QUAGGIO, J.A. Métodos de análise de solo para fins de fertilidade. Campinas: Instituto Agronômico, 1983. 31p. (Boletim Técnico, 81).

SÁ, J.C.M. Manejo da fertilidade do solo no sistema plantio direto. In: SIQUEIRA, J.O.; MOREIRA, F.M.S.; LOPES, A.S.; GUILHERME, L.R.G.; FAQUIN, V.; FURTINI NETO, A.E.; CARVALHO, J.G. (Eds.) Inter-relação fertilidade, biologia do solo e nutrição de plantas. Viçosa: SBCS, Lavras: UFLA/SBCS, 1999. p.267-321. 
SÁ, M.E. de. Importância da adubação nitrogenada na qualidade de sementes. In: SÁ, M.E.de; BUZZETTI, S. (Coord.). Importância da adubação na qualidade dos produtos agrícolas. São Paulo: Icone, 1994. p.65-98.

STURGIS, F.E.; MIEARS, R.J.; WALKER, R.K. Protein in rice as influenced by variety and fertilizer levels. Louisiana Experimental Station Technical Bulletin, Louisiana, 1952. 466p.
TEIXEIRA, I.R.; ANDRADE, M.J.B. de; CARVALHO, J.G. de; MORAIS, A.R. de; CORRÊA, J.B.D. Resposta do feijoeiro (Phaseolus vulgaris L. cv. pérola) a diferentes densidades de semeadura e doses de nitrogênio. Ciência e Agrotecnologia, v.24, n.2, p.399-408, 2000.

VIEIRA, R.F.; VIEIRA, C.; RAMOS, J.A.O. Produção de sementes de feijão. Viçosa: EPAMIG/EMBRAPA, 1993. $131 \mathrm{p}$. 